Pontifícia Universiqage Católica

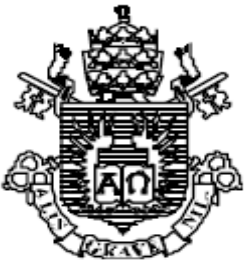

Thaís Valéria Barreiros Alves

Estudo de Complexos Binários de Alumínio(III) com Aminoácidos Sulfurados e Ligantes Fosfatados

\author{
Dissertação de Mestrado \\ Dissertação apresentada ao Programa de Pós- \\ graduação em Química da PUC-Rio como \\ requisito parcial para obtenção do Título de \\ Mestre em Química.
}

Orientadora: Prof ${ }^{a}$. Judith Felcman

Rio de Janeiro

Fevereiro de 2010 
Pontifícia Universidade $_{\text {do Rio de Janejón }}$

Thaís Valéria Barreiros Alves

\section{Estudo de Complexos Binários de Alumínio(III) com Aminoácidos Sulfurados e Ligantes Fosfatados}

Dissertação apresentada como requisito parcial para obtenção do grau de Mestre pelo Programa de Pós-Graduação em Química da PUC-Rio. Aprovada pela Comissão Examinadora abaixo assinada.

Profa . Judith Felcman

Orientadora

Departamento de Química - PUC-Rio

Profa. Andréa de Moraes Silva

IFRJ

Profa. Annelise Casellato Instituto de Química - UFRJ

Prof. Nicolás A. Rey

Departamento de Química - PUC-Rio

Prof. Jose Eugenio Leal Coordenador Setorial de Pós-Graduação do

Centro Técnico Científico - PUCC-Rio

Rio de Janeiro, 01 de fevereiro de 2010 
Todos os direitos reservados. É proibida a reprodução total ou parcial do trabalho sem autorização da universidade, da autora e da orientadora.

Thaís Valéria Barreiros Alves

Graduou-se em Licenciatura em Química no Instituto Federal de Educação, Ciência e Tecnologia do Rio de Janeiro em 2007, em Nutrição na Universidade Federal do Estado do Rio de Janeiro em 2007 e em Bacharelado em Química com Atribuição Tecnológica na Universidade do Grande Rio em 2008. Ingressou no Mestrado em Química com ênfase em Química Inorgânica na PUC-Rio em 2008.

Ficha Catalográfica

Alves, Thaís Valéria Barreiros

Estudo de complexos binários de alumínio(III) com aminoácidos sulfurados e ligantes fosfatados / Thaís Valéria Barreiros Alves; orientador: Judith Felcman. 2010.

319 f. : il. (color.) ; $30 \mathrm{~cm}$

Dissertação (Mestrado em Química) - Pontifícia Universidade Católica do Rio de Janeiro, Rio de Janeiro, 2010.

Inclui bibliografia.

1. Química - Teses. 2. Complexos binários. 3. Alumínio(III). 4. Aminoácidos sulfurados. 5. Fosfocreatina. 6. Adenosina 5'-trifosfato. 7. Constantes de estabilidade. 8. Espectroscopia Raman. 9. Modelagem molecular. 10. Cálculos ab initio. I. Felcman, Judith. II. Pontifícia Universidade Católica do Rio de Janeiro. Departamento de Química. III. Título. 


\section{Agradecimentos}

A Deus.

A minha mãe Sonia Maria Alves e ao meu pai Celso Alves que me deram tudo e me apoiaram desde o começo. Agradeço pelo amor inenarrável e pelos conselhos imprescindíveis.

Ao meu irmão Henrique Alves pela cumplicidade, apoio e carinho.

Aos demais familiares.

Ao meu esposo André Tenório pelo apoio técnico, pela compreensão, por cada minuto ao meu lado e pela oportunidade de amá-lo.

A Lília e Marcel pela afeição.

Ao melhor amigo Pingo.

A minha amiga Josy que nunca deixou de estar ao meu lado.

À professora Dra. Judith Felcman pela compreensão e atenção.

À professora Dra. Andréa de Moraes pelo carinho.

Ao professor Dr. Luciano Lião (UFG) pela colaboração nos estudos de RMN.

Aos colegas de laboratório.

Aos membros da comissão examinadora.

Aos professores e funcionários do Departamento de Química.

Ao CNPq e à PUC-Rio, pelos auxílios concedidos, sem os quais este trabalho não poderia ser realizado. 


\section{Resumo}

Alves, Thaís Valéria Barreiros; Felcman, Judith. Estudo de complexos binários de Alumínio(III) com aminoácidos sulfurados e ligantes fosfatados. Rio de Janeiro, 2010. 319p. Dissertação de Mestrado Departamento de Química, Pontifícia Universidade Católica do Rio de Janeiro.

O estudo de complexos binários de $\mathrm{Al}$ (III) com aminoácidos sulfurados (metionina, cisteína, homocisteína e penicilamina) e ligantes fosfatados (adenosina 5'-trifosfato e fosfocreatina) foi feito em solução aquosa por meio de titulações potenciométricas, de $\mathrm{RMN}$ de ${ }^{13} \mathrm{C}$ e ${ }^{27} \mathrm{Al}$, de espectroscopia Raman, de modelagem molecular e de cálculos teóricos do espectro vibracional através do procedimento de cálculo DFT: B3LYP/6-311G. As titulações potenciométricas e

o RMN de ${ }^{13} \mathrm{C} \mathrm{e}{ }^{27} \mathrm{Al}$ foram obtidos apenas para os complexos contendo aminoácidos. Através da potenciometria determinaram-se as constantes de estabilidade dos complexos binários de $\mathrm{Al}$ (III) com os aminoácidos e suas curvas de distribuição de espécies. Ao se analisar os valores de constantes obtidos percebe-se que o complexo Al-Penicilamina apresenta um valor maior que os demais complexos formados, indicando um comportamento distinto. Propôs-se que a penicilamina atuaria como tridentada através dos átomos de oxigênio do carboxilato, de nitrogênio da amina e de enxofre da sulfidrila, enquanto os outros atuariam como bidentados coordenando-se através dos átomos de oxigênio do carboxilato e de nitrogênio da amina. As distribuições de espécies em função do pH mostraram que no pH fisiológico há a predominância das espécies hidrolisadas do metal e do complexo. Os espetros de $\mathrm{RMN}$ de ${ }^{13} \mathrm{C}$ e de Raman e os cálculos teóricos confirmaram a possibilidade dos sítios coordenativos propostos para os aminoácidos. O RMN de ${ }^{27} \mathrm{Al}$ e a modelagem molecular mostraram que a geometria adotada pelo centro metálico é a octaédrica distorcida. Para os ligantes fosfatados, a espectroscopia Raman, a modelagem molecular e os cálculos teóricos indicaram que no complexo com a adenosina 5'-trifosfato a geometria deve ser octaédrica distorcida, com o ligante comportando-se como bidentado através dos átomos de oxigênio dos fosfatos terminais $\beta$ e $\gamma$. Já no complexo com 
a fosfocreatina, a geometria deve ser tetraédrica distorcida, com o ligante comportando-se como tridentado coordenando-se pelos átomos de oxigênio do grupamento fosfato, de oxigênio do grupamento carboxilato e de nitrogênio do grupamento guanidino. Estes resultados mostram a variedade do comportamento dos ligantes na complexação com o $\mathrm{Al}(\mathrm{III})$.

\section{Palavras-chave}

Complexos binários; alumínio(III); aminoácidos sulfurados; fosfocreatina; adenosina 5'-trifosfato; constantes de estabilidade; espectroscopia Raman; espectroscopia de RMN; modelagem molecular; cálculos ab initio. 


\section{Abstract}

Alves, Thaís Valéria Barreiros; Felcman, Judith (Advisor). Study of binary complexes of Aluminum(III) with sulfur amino acids and phosphate ligands. Rio de Janeiro, 2010. 319 p. MSc Dissertation - Departamento de Química, Pontifícia Universidade Católica do Rio de Janeiro.

The study of binary complexes of $\mathrm{Al}$ (III) with sulfur amino acids (methionine, cysteine, homocysteine and penicillamine) and phosphate ligands (adenosine 5'-triphosphate and phosphocreatine) was done in aqueous solution applying potentiometric titrations, ${ }^{13} \mathrm{C}$ and ${ }^{27} \mathrm{Al}$ NMR, Raman spectroscopy, molecular modeling and DFT: B3LYP/6-311G theoretical calculations of the vibrational spectra. The potentiometric titrations and ${ }^{13} \mathrm{C}$ and ${ }^{27} \mathrm{Al}$ NMR were performed only for the complexes with amino acids. The potentiometry was used to determine the stability constants of the $\mathrm{Al}(\mathrm{III})$-amino acid binary complexes and the distribution graphs of their species. The comparison between the values obtained for the constants revealed a distinct behavior for the Al-Penicillamine complex, with higher stability constants than the other complexes. It is suggested that penicillamine might act as a tridentate ligand through the oxygen of the carboxylate, the nitrogen of the amine and the sulfur of the sulfhydryl, while others act as bidentate ligands coordinating through the oxygen of the carboxylate and the nitrogen of the amine. The graphs of the species distribution in function of $\mathrm{pH}$ showed that in biological $\mathrm{pH}$ there is a predominance of hydrolyzed species of the metal and the complex. Raman and ${ }^{13} \mathrm{C}$ NMR spectroscopy associated with theoretical calculations confirmed the coordination sites proposed for the amino acids. ${ }^{27} \mathrm{Al}$ NMR and molecular modeling showed that the geometry adopted by the metal center is distorted octahedral. For phosphate ligands, Raman spectroscopy, molecular modeling and theoretical calculations indicated that the geometry of adenosine 5'-triphosphate complex can be distorted octahedral with the ligand behaving as bidentate through one oxygen atom of each terminal $\beta$ and $\gamma$ phosphates. Nevertheless, for the phosphocreatine complex the geometry seems 
to be a distorted tetrahedron with the ligand behaving as a tridentate, one coordinating through one of the oxygens in the phosphate, the oxygen in the carboxylate and the nitrogen in the guanidine group. These results bring to light the multiplicity of ligand behaviors in the complexation with $\mathrm{Al}(\mathrm{III})$.

\section{Keywords}

Binary complexes; aluminum(III); sulfur amino acids; phosphocreatine; adenosine 5'-triphosphate; stability constants; Raman spectroscopy; NMR spectroscopy; molecular modeling; ab initio calculations. 


\section{Sumário}

1 Introdução 25

1.1. Objetivos 26

2 Ligantes $\quad 27$

2.1. Aminoácidos Sulfurados 27

2.1.1. Metionina 30

2.1.2. Cisteína 34

2.1.3. Homocisteína 36

2.1.4. Penicilamina 38

2.2. Ligantes Fosfatados $\quad 40$

2.2.1. Adenosina 5'-trifosfato 44

$\begin{array}{ll}\text { 2.2.2. Fosfocreatina } & 48\end{array}$

3 Íon metálico em estudo: Alumínio(III) 52

3.1. Hidrólise do Íon Alumínio(III) 52

3.2. Características Biológicas 53

3.3. Doença de Alzheimer 57

3.4. Doença de Alzheimer e o Íon Alumínio(III) 63

4 Programas computacionais $\quad 70$

4.1. Hyperquad 2000

4.2. Hyss 2006

4.3. GaussView 3.0

4.4. Gaussian 03W 73

4.5. Chemcraft 75

4.6. Origin 6.0

5 Experimental $\quad 76$

5.1. Reagentes Utilizados 76

5.2. Aparelhagens Utilizadas $\quad 77$

5.3. Metodologia $\quad 77$

5.3.1. Titulação Potenciométrica 80 
5.3.3. Espectroscopia de Ressonância Magnética Nuclear 82

6 Resultados e Discussão do Estudo Potenciométrico 85

6.1. Estudo Potenciométrico dos Ligantes Puros 85

6.1.1. Aminoácidos Sulfurados 85

6.2. Complexos Binários com o ĺon Alumínio(III) 91

6.2.1.Espécies Hidrolisadas do Íon Alumínio(III) 92

6.2.2 Complexos do Íon Alumínio(III) com os Aminoácidos Sulfurados $\quad 92$

7 Estudo Estrutural e Espectral de Complexos Binários com o Íon Alumínio(III) através da Espectroscopia Raman e Cálculos Ab initio (DFT: B3LYP/6-311G)

7.1. Estudo Estrutural e Espectral do Cátion Complexo $\left[\mathrm{Al}(\mathrm{Met})\left(\mathrm{H}_{2} \mathrm{O}\right)_{4}\right]^{2+}$ através de Espectroscopia Raman e Cálculos Ab initio (DFT: B3LYP/6-311G)

7.2. Estudo Estrutural e Espectral do Cátion Complexo $\left[\mathrm{Al}(\mathrm{Cis})\left(\mathrm{H}_{2} \mathrm{O}\right)_{4}\right]^{2+}$ através da Espectroscopia Raman e Cálculos Ab initio (DFT: B3LYP/6-311G)

7.3. Estudo Estrutural e Espectral do Cátion Complexo $\left[\mathrm{Al}(\mathrm{Hcis})\left(\mathrm{H}_{2} \mathrm{O}\right)_{4}\right]^{2+}$ através da Espectroscopia Raman e Cálculos Ab initio (DFT: B3LYP/6-311G)

7.4. Estudo Estrutural e Espectral do Cátion Complexo $\left[\mathrm{Al}(\mathrm{Pen})\left(\mathrm{H}_{2} \mathrm{O}\right)_{3}\right]^{+}$através da Espectroscopia Raman e Cálculos $A b$ initio (DFT: B3LYP/6-311G)

7.5. Discussão Geral das Geometrias Estruturais dos Complexos Sulfurados ML Obtidos pelos Cálculos Ab initio (DFT: B3LYP/6-311G)

7.6. Estudo Estrutural e Espectral do Cátion Complexo $\left[\mathrm{Al}(\mathrm{PCr})\left(\mathrm{H}_{2} \mathrm{O}\right)\right]^{+}$através da Espectroscopia Raman e Cálculos Ab initio (DFT: B3LYP/6-311G)

7.7. Estudo Estrutural e Espectral do Cátion Complexo $\left[\mathrm{Al}(\mathrm{ATP})\left(\mathrm{H}_{2} \mathrm{O}\right)_{4}\right]^{+}$através da Espectroscopia Raman e Cálculos $A b$ initio (DFT: B3LYP/6-311G) 
8.1. Avaliação da Capacidade Coordenativa dos Átomos dos Ligantes Participantes da Coordenação com o Íon Alumínio(III)

8.2. Espectroscopia de Ressonância Magnética Nuclear de ${ }^{13} \mathrm{C}$ e ${ }^{27} \mathrm{Al}$

8.2.1. Espectroscopia de Ressonância Magnética Nuclear de ${ }^{13} \mathrm{C}$ do Ligante IDA e do Complexo AlIDA

8.2.2. Espectroscopia de Ressonância Magnética Nuclear de ${ }^{13} \mathrm{C}$ do Ligante MIDA (Carbono Acoplado) e do Complexo AIMIDA

8.2.3. Espectroscopia de Ressonância Magnética Nuclear de 13C e 27Al dos Aminoácidos Sulfurados e dos Complexos Al-Aminoácidos Sulfurados (Aminoácidos = Cisteína, Homocisteína, Penicilamina e Metionina)

8.2.3.1. Espectroscopia de Ressonância Magnética Nuclear de $13 \mathrm{C}$ e $27 \mathrm{Al}$ do Ligante Metionina e do Complexo AlMetionina

8.2.3.2. Espectroscopia de Ressonância Magnética Nuclear de 13C e 27Al do Ligante Cisteína e do Complexo AlCisteína

8.2.3.3. Espectroscopia de Ressonância Magnética Nuclear de $13 \mathrm{C}$ e $27 \mathrm{Al}$ do Ligante Homocisteína e do Complexo AlHomocisteína

8.2.3.4. Espectroscopia de Ressonância Magnética Nuclear de ${ }^{13} \mathrm{C} \mathrm{e}{ }^{27} \mathrm{Al}$ do Ligante Penicilamina e do Complexo AlPenicilamina

10 Referências Bibliográficas

10.1. Introdução 264

10.2. Ligantes 265

10.3. Íon metálico em estudo: Alumínio(III) 268

10.4. Programas computacionais 270

10.5. Experimental 271

10.6. Resultados e Discussão do Estudo Potenciométrico 272 
10.7. Estudo Estrutural e Espectral de Complexos Binários com o Íon Alumínio(III) através da Espectroscopia Raman e Cálculos Ab initio (DFT: B3LYP/6-311G) 273

10.8. Discussão Geral 275

11 Anexos 276

11.1. Dados Potenciométricos 276

11.2. Dados Espectroscópicos (Raman e DFT: B3LYP/6-311G) 279

11.3. Dados Espectroscópicos (Segunda derivada dos espectros Raman dos complexos) 314

11.4. Dados Espectroscópicos da Ressonância Magnética (RMN de ${ }^{27} \mathrm{Al}$ ) 


\section{Lista de figuras}

Figura 2.1 - Aminoácidos sulfurados em estudo

Figura 2.2 - Produtos das reações de estresse oxidativo sobre os aminoácidos sulfurados em estudo

Figura 2.3 - Metabolismo da Metionina

Figura 2.4 - Metabolismo da homocisteína e possível mecanismo da doença aterotrombótica

Figura 2.5 - RMI do cérebro de paciente com Doença de Wilson 39

Figura 2.6 - Ligantes fosfatados em estudo 41

Figura 2.7 - Ciclo do ácido tricarboxílico 45

Figura 2.8 - Geração líquida de adenosina 5'-trifosfato 46

Figura 2.9 - Reações envolvendo o ATP e a fosfocreatina na contração muscular 49

Figura 3.1 - Placa senil cercada por estruturas neurofibrilares 58

Figura 3.2 - Sequência de aminoácidos da proteína Aß42 59

Figura 3.3 - Esquema do processamento da APP 59

Figura 3.4 - Estrutura da dimebolina 60

Figura 3.5 - RMI da evolução metabólica de um cérebro acometido por Alzheimer 61

Figura 3.6 - Tecido cerebral com Alzheimer e sadio 62

Figura 3.7 - Cérebro com Alzheimer e sadio 63

Figura 3.8 - Características do tecido cerebral humano com conteúdos de alumínio

Figura 5.1 - Espalhamento de luz $\quad 81$

Figura 6.1 - Curvas de titulação potenciométrica dos aminoácidos Met, Cis, Hcis e Pen

Figura 6.2 - Curva de titulação potenciométrica do aminoácido glicina

Figura 6.3 - Distribuição de espécies em função do $\mathrm{pH}$ para os aminoácidos Met, Cis, Hcis e Pen

Figura 6.4 - Curvas de titulação experimental e calculada para os aminoácidos Met, Cis, Hcis e Pen

Figura 6.5 - Curvas de titulação potenciométrica dos sistemas binários de aminoácidos sulfurados com íon alumínio(III) na proporção 1:5 
Figura 6.6 - Curvas de titulação potenciométrica dos sistemas binários de aminoácidos sulfurados com íon alumínio(III) na proporção 1:1

Figura 6.7 - Estruturas propostas dos complexos formados com o aminoácido metionina

Figura 6.8 - Estruturas propostas dos complexos formados com o aminoácido cisteína

Figura 6.9 - Estruturas propostas dos complexos formados com o aminoácido homocisteína

Figura 6.10 - Estruturas propostas dos complexos formados com o aminoácido penicilamina

Figura 6.11 - Modelo de coordenação dos aminoácidos

Figura 6.12 - Distribuição de espécies em função do pH para o sistema Al:Met concentrada

102

Figura 6.13 - Distribuição de espécies em função do pH para o sistema Al:Cis concentrada

Figura 6.14 - Distribuição de espécies em função do pH para o sistema Al:Hcis concentrada

Figura 6.15 - Distribuição de espécies em função do pH para o sistema Al:Pen concentrada

Figura 6.16 - Distribuição de espécies em função do pH para o sistema Al:Met

Figura 6.17 - Distribuição de espécies em função do pH para o sistema Al:Cis

Figura 6.18 - Distribuição de espécies em função do pH para o sistema Al:Hcis

Figura 6.19 - Distribuição de espécies em função do pH para o sistema Al:Pen

Figura 6.20 - Curvas de titulação experimental e calculada para o sistema binário Al:Met concentrada

Figura 6.21 - Curvas de titulação experimental e calculada para o sistema binário Al:Cis concentrada

Figura 6.22 - Curvas de titulação experimental e calculada para o sistema binário Al:Hcis concentrada

Figura 6.23 - Curvas de titulação experimental e calculada para o sistema binário Al:Pen concentrada

Figura 6.24 - Curvas de titulação experimental e calculada para o sistema binário Al:Met 
Figura 6.25 - Curvas de titulação experimental e calculada para o sistema binário $\mathrm{Al}: \mathrm{Cis}$

Figura 6.26 - Curvas de titulação experimental e calculada para o sistema binário Al:Hcis

Figura 6.27 - Curvas de titulação experimental e calculada para o sistema binário Al:Pen

Figura 7.1 - Distribuição de espécies em função do pH para o sistema Al:Met

Figura 7.2 - Distribuição de espécies em função do pH para o sistema Al:Cis

Figura 7.3 - Distribuição de espécies em função do pH para o sistema Al:Hcis

Figura 7.4 - Distribuição de espécies em função do pH para o sistema Al:Pen

Figura 7.5 - Distribuição de espécies em função do pH para o sistema Al:PCr

Figura 7.6 - Distribuição de espécies em função do pH para o sistema Al:ATP

Figura 7.7 - Espectro Raman da água bidestilada e deionizada

Figura 7.8 - Espectro Raman da solução de nitrato de alumínio

Figura 7.9 - Modelagem molecular do complexo

$$
\left[\mathrm{Al}(\mathrm{Met})\left(\mathrm{H}_{2} \mathrm{O}\right)_{4}\right]^{2+} \text { (a) e do ligante metionina (b) }
$$

Figura 7.10 - Espectro Raman do ligante metionina em solução 120

Figura 7.11 - Espectro Raman do ligante metionina no estado sólido

Figura 7.12 - Espectro calculado do ligante metionina

Figura 7.13 - Espectro Raman do sistema binário alumínio e metionina em solução $\mathrm{pH}=3,5$

Figura 7.14 - Espectro Raman deconvoluído do sistema binário alumínio e metionina da região de 3500 a $2800 \mathrm{~cm}^{-1}$

Figura 7.15 - Espectro Raman deconvoluído do sistema binário alumínio e metionina da região de 1700 a $900 \mathrm{~cm}^{-1}$

Figura 7.16 - Espectro calculado do sistema binário alumínio e metionina

Figura 7.17 - Geometrias distorcidas de alguns modos normais do complexo $\left[\mathrm{Al}(\mathrm{Met})\left(\mathrm{H}_{2} \mathrm{O}\right)_{4}\right]^{2+}$ 
Figura 7.18 - Modelagem molecular do complexo

$$
\left[\mathrm{Al}(\mathrm{Cis})\left(\mathrm{H}_{2} \mathrm{O}\right)_{4}\right]^{2+} \text { (a) e do ligante cisteína (b) } 135
$$

Figura 7.19 - Espectro Raman do ligante cisteína em solução 136

Figura 7.20 - Espectro Raman do ligante cisteína no estado sólido

Figura 7.21 - Espectro calculado do ligante cisteína

Figura 7.22 - Espectro Raman do sistema binário alumínio e cisteína em solução $\mathrm{pH}=2,8$

Figura 7.23 - Espectro Raman deconvoluído do sistema binário alumínio e cisteína

Figura 7.24 - Espectro calculado do sistema binário alumínio e cisteína

Figura 7.25 - Geometrias distorcidas de alguns modos normais do complexo $\left[\mathrm{Al}(\mathrm{Cis})\left(\mathrm{H}_{2} \mathrm{O}\right)_{4}\right]^{2+}$

Figura 7.26 - Modelagem molecular do complexo $\left[\mathrm{Al}(\mathrm{Hcis})\left(\mathrm{H}_{2} \mathrm{O}\right)_{4}\right]^{2+}$ (a) e do ligante homocisteína (b) 149

Figura 7.27 - Espectro Raman do ligante homocisteína em solução

Figura 7.28 - Espectro Raman do ligante homocisteína no estado sólido

Figura 7.29 - Espectro calculado do ligante homocisteína 152

Figura 7.30 - Espectro Raman do sistema binário alumínio e homocisteína em solução $\mathrm{pH}=2,6$

Figura 7.31 - Espectro Raman deconvoluído do sistema binário alumínio e homocisteína

Figura 7.32 - Espectro calculado do sistema binário alumínio e homocisteína

Figura 7.33 - Geometrias distorcidas de alguns modos normais do complexo $\left[\mathrm{Al}(\mathrm{Hcis})\left(\mathrm{H}_{2} \mathrm{O}\right)_{4}\right]^{2+}$

Figura 7.34 - Modelagem molecular do complexo fac- $\left[\mathrm{Al}(\mathrm{Pen})\left(\mathrm{H}_{2} \mathrm{O}\right)_{3}\right]^{+}$(a) e do ligante penicilamina (b) 165

Figura 7.35 - Espectro Raman do ligante penicilamina em solução $\quad 166$

Figura 7.36 - Espectro Raman do ligante penicilamina no estado sólido

Figura 7.37 - Espectro calculado do ligante penicilamina 
Figura 7.38 - Espectro Raman do sistema binário alumínio e penicilamina em solução $\mathrm{pH}=2,7$

Figura 7.39 - Espectro Raman deconvoluído do sistema binário alumínio e penicilamina da região de 3500 a $2800 \mathrm{~cm}^{-1}$

Figura 7.40 - Espectro Raman deconvoluído do sistema binário alumínio e penicilamina da região de 1700 a $100 \mathrm{~cm}^{-1}$

Figura 7.41 - Espectro calculado do sistema binário alumínio e penicilamina

Figura 7.42 - Geometrias distorcidas de alguns modos normais do complexo fac- $\left[\mathrm{Al}(\mathrm{Pen})\left(\mathrm{H}_{2} \mathrm{O}\right)_{3}\right]^{+}$

Figura 7.43 - Modelagem molecular do complexo $\left[\mathrm{Al}(\mathrm{PCr})\left(\mathrm{H}_{2} \mathrm{O}\right)\right]^{+}(\mathrm{a})$ e do ligante fosfocreatina (b)

Figura 7.44 - Espectro Raman do ligante fosfocreatina em solução

Figura 7.45 - Espectro Raman do ligante fosfocreatina no estado sólido

Figura 7.46 - Espectro calculado do ligante fosfocreatina

Figura 7.47 - Espectro Raman do sistema binário alumínio e fosfocreatina em solução $\mathrm{pH}=4,5$

Figura 7.48 - Espectro Raman deconvoluído do sistema binário alumínio e fosfocreatina da região de 3500 a $2800 \mathrm{~cm}^{-1}$

Figura 7.49 - Espectro Raman deconvoluído do sistema binário alumínio e fosfocreatina da região de 1800 a $100 \mathrm{~cm}^{-1}$

Figura 7.50 - Espectro calculado do sistema binário alumínio e fosfocreatina

Figura 7.51 - Geometrias distorcidas de alguns modos normais do complexo $\left[\mathrm{Al}(\mathrm{PCr})\left(\mathrm{H}_{2} \mathrm{O}\right)\right]^{+}$com seus

vetores de deslocamento

Figura 7.52 - Modelagem molecular do complexo [Al(ATP) $\left.\left(\mathrm{H}_{2} \mathrm{O}\right)_{4}\right]^{+}$(a) e do ligante adenosina 5'-trifosfato (b)

Figura 7.53 - Espectro Raman do ligante adenosina 5'- trifosfato em solução

Figura 7.54 - Espectro Raman do ligante adenosina 5'- trifosfato no estado sólido 
Figura 7.55 - Espectro calculado do ligante adenosina

5 '- trifosfato

206

Figura 7.56 - Espectro Raman do sistema binário alumínio e adenosina 5 ' -trifosfato em solução $\mathrm{pH}=3,0$

206

Figura 7.57 - Espectro Raman deconvoluído do sistema binário alumínio e adenosina 5'- trifosfato da região de 3500 a $2900 \mathrm{~cm}^{-1}$

207

Figura 7.58 - Espectro Raman deconvoluído do sistema binário alumínio e adenosina 5'- trifosfato da região de 1800 a $100 \mathrm{~cm}^{-1}$

207

Figura 7.59 - Espectro calculado do sistema binário alumínio e adenosina 5'- trifosfato

Figura 7.60 - Geometrias distorcidas de alguns modos normais do complexo $\left[\mathrm{Al}(\mathrm{ATP})\left(\mathrm{H}_{2} \mathrm{O}\right)_{4}\right]^{+}$com seus vetores de deslocamento

Figura 8.1 - Ligantes agrupados para a avaliação dos átomos participantes da coordenação com o íon Al(III)

Figura 8.2 - Gráfico de capacidade coordenativa dos átomos dos ligantes nos complexos formados entre o $\mathrm{Al}(\mathrm{III})$ e ligantes bi, tri e tetradentados

225

Figura 8.3 - Ligante IDA 228

Figura 8.4 - Espectro RMN de ${ }^{13} \mathrm{C}$ do ligante IDA 228

Figura 8.5 - Deslocamentos químicos característicos da RMN de ${ }^{13} \mathrm{C}$ 229

Figura 8.6 - Atribuições dos picos em ppm para o ligante IDA 230

Figura 8.7 - Estrutura proposta para o AlIDA

230

Figura 8.8 - Espectro RMN de ${ }^{13} \mathrm{C}$ do complexo AlIDA 231

Figura 8.9 - Atribuições dos picos em ppm para o complexo AlIDA 232

Figura 8.10 - Espectro RMN de ${ }^{13} \mathrm{C}$ do complexo AlIDA 232

Figura 8.11 - Espectro RMN de ${ }^{13} \mathrm{C}$ do complexo AlIDA 233

Figura 8.12 - Ligante MIDA 234

Figura 8.13 - Espectro RMN de C do ligante MIDA (Carbono acoplado)

Figura 8.14 - Espectro RMN de C do ligante MIDA (Carbono acoplado)

Figura 8.15 - Atribuições dos picos em ppm para o ligante MIDA 
Figura 8.16 - Estrutura proposta para o complexo AIMIDA

Figura 8.17 - Espectro RMN de ${ }^{13} \mathrm{C}$ do complexo AIMIDA

Figura 8.18 - Atribuições dos picos em ppm para o complexo AIMIDA

239

Figura 8.19 - Ligante metionina

Figura 8.20 - RMN de ${ }^{13} \mathrm{C}$ do ligante metionina

Figura 8.21 - Atribuições dos picos em ppm para o ligante metionina

Figura 8.22 - Estrutura proposta para o complexo AlMetionina

242

Figura 8.23 - RMN de ${ }^{13} \mathrm{C}$ do sistema alumínio e metionina

242

Figura 8.24 - Atribuições dos picos para o complexo AlMetionina 243

Figura 8.25 - RMN de ${ }^{13} \mathrm{C}$ do sistema alumínio e metionina 243

Figura 8.26 - RMN de ${ }^{27} \mathrm{Al}$ do sistema alumínio e metionina 244

Figura 8.27 - Ligante cisteína 245

Figura 8.28 - RMN de ${ }^{13} \mathrm{C}$ do ligante cisteína 246

Figura 8.29 - Atribuições dos picos em ppm para o ligante cisteína

246

Figura 8.30 - Estrutura proposta para o complexo AICisteína 247

Figura 8.31 - RMN de ${ }^{13} \mathrm{C}$ do sistema alumínio e cisteína 247

Figura 8.32 - Atribuições dos picos para o complexo AlCisteína 248

Figura 8.33 - RMN de ${ }^{13} \mathrm{C}$ do sistema alumínio e cisteína 248

Figura 8.34 - RMN de ${ }^{27} \mathrm{Al}$ do sistema alumínio e cisteína 249

Figura 8.35 - Ligante homocisteína 250

Figura 8.36 - RMN de ${ }^{13} \mathrm{C}$ do ligante homocisteína 251

Figura 8.37 - Atribuições dos picos em ppm para o ligante homocisteína

251

Figura 8.38 - Estrutura proposta para o complexo AlHomocisteína 252

Figura 8.39 - RMN de ${ }^{13} \mathrm{C}$ do sistema alumínio e homocisteína 252

Figura 8.40 - Atribuições dos picos para o complexo AlHomocisteína 253

Figura 8.41 - RMN de ${ }^{13} \mathrm{C}$ do sistema alumínio e homocisteína 253

Figura 8.42 - RMN de ${ }^{27} \mathrm{Al}$ do sistema alumínio e homocisteína 254

Figura 8.43 - Ligante penicilamina 
Figura 8.44 - RMN de ${ }^{13} \mathrm{C}$ do ligante penicilamina

Figura 8.45 - Atribuições dos picos em ppm para o ligante penicilamina

256

Figura 8.46 - Estrutura proposta para o complexo AlPenicilamina 256

Figura 8.47 - RMN de ${ }^{13} \mathrm{C}$ do sistema alumínio e penicilamina 257

Figura 8.48 - Atribuições dos picos para o complexo AlPenicilamina 257

Figura 8.49- RMN de ${ }^{13} \mathrm{C}$ do sistema alumínio e penicilamina 258

Figura $8.50-\mathrm{RMN}$ de ${ }^{13} \mathrm{C}$ do sistema alumínio e penicilamina 258

Figura 8.51 - RMN de ${ }^{27} \mathrm{Al}$ do sistema alumínio e penicilamina 259

Figura A.1 - Segunda derivada do espectro Raman do sistema binário alumínio e metionina da região de 3500 a $2900 \mathrm{~cm}^{-1}$

314

Figura A.2 - Segunda derivada do espectro Raman do sistema binário alumínio e metionina da região de 1700 a $100 \mathrm{~cm}^{-1}$

Figura A.3 - Segunda derivada do espectro Raman do sistema binário alumínio e cisteína

Figura A.4 - Segunda derivada do espectro Raman do sistema binário alumínio e homocisteína

Figura A.5 - Segunda derivada do espectro Raman do sistema binário alumínio e penicilamina da região de 3500 a $2800 \mathrm{~cm}^{-1}$

Figura A.6 - Segunda derivada do espectro Raman do sistema binário alumínio e penicilamina da região de 1700 a $100 \mathrm{~cm}^{-1}$

Figura A.7 - Segunda derivada do espectro Raman do sistema binário alumínio e fosfocreatina da região de 3500 a $2900 \mathrm{~cm}^{-1}$

Figura A.8 - Segunda derivada do espectro Raman do sistema binário alumínio e fosfocreatina da região de 1700 a $100 \mathrm{~cm}^{-1}$

Figura A.9 - Segunda derivada do espectro Raman do sistema binário alumínio e adenosina 5 '- trifosfato da região de 3500 a $2500 \mathrm{~cm}^{-1}$

Figura A.10 - Segunda derivada do espectro Raman do sistema binário alumínio e adenosina 5 '- trifosfato da região de 1800 a $100 \mathrm{~cm}^{-1}$

Figura A.11 - RMN de ${ }^{27} \mathrm{Al}$ da solução de nitrato de alumínio 


\section{Lista de tabelas}

Tabela 2.1 - Energias livres para as hidrólises de alguns compostos fosfatados $(\mathrm{pH} 7,0)$

Tabela 6.1 - Equilíbrios de dissociação dos aminoácidos Met, Cis, Hcis e Pen

Tabela 6.2 - Constantes de dissociação dos aminoácidos Met, Cis, Hcis e Pen

Tabela 6.3 - Constantes de formação das espécies hidrolisadas do íon $\mathrm{Al}(\mathrm{III})$ usadas nos cálculos de complexos

Tabela 6.4 - Constantes de estabilidade para os complexos formados entre o íon alumínio(III) e os aminoácidos sulfurados: Espécies protonadas e $\mathrm{ML}, \mathrm{ML}_{2}, \mathrm{ML}_{3}$

Tabela 6.5 - Constantes de estabilidade $(\log \beta)$ para os complexos formados entre o íon alumínio(III) e os aminoácidos sulfurados: Espécies hidrolisadas

Tabela 6.6 - Valores de log $\beta$ da literatura para os complexos entre os aminoácidos sulfurados e o íon alumínio(III)

Tabela 6.7 - Valores de log $\beta_{\mathrm{ML}}$ para o $\mathrm{Al}(\mathrm{III})$ e para os complexos entre os aminoácidos sulfurados e outros íons metálicos (III)

Tabela 7.1 - Parâmetros geométricos calculados (comprimentos de ligação em $\AA$ ) para o complexo $\left[\mathrm{Al}(\mathrm{Met})\left(\mathrm{H}_{2} \mathrm{O}\right)_{4}\right]^{2+}$ e para o ligante metionina

Tabela 7.2 - Parâmetros geométricos calculados (ângulos de ligação em graus) para o complexo $\left[\mathrm{Al}(\mathrm{Met})\left(\mathrm{H}_{2} \mathrm{O}\right)_{4}\right]^{2+}$ e para o ligante metionina

Tabela 7.3 - Espectro vibracional Raman experimental e calculado para o complexo $\left[\mathrm{Al}(\mathrm{Met})\left(\mathrm{H}_{2} \mathrm{O}\right)_{4}\right]^{2+}$

Tabela 7.4 - Parâmetros geométricos calculados (comprimentos de ligação em $\AA$ ) para o complexo $\left[\mathrm{Al}(\mathrm{Cis})\left(\mathrm{H}_{2} \mathrm{O}\right)_{4}\right]^{2+}$ e para o ligante cisteína

Tabela 7.5 - Parâmetros geométricos calculados (ângulos de ligação em graus) para o complexo $\left[\mathrm{Al}(\mathrm{Cis})\left(\mathrm{H}_{2} \mathrm{O}\right)_{4}\right]^{2+}$ e para o ligante cisteína

Tabela 7.6 - Espectro vibracional Raman experimental e calculado para o complexo $\left[\mathrm{Al}(\mathrm{Cis})\left(\mathrm{H}_{2} \mathrm{O}\right)_{4}\right]^{2+}$ 
Tabela 7.7 - Parâmetros geométricos calculados (comprimentos de ligação em $\AA$ ) para o complexo $\left[\mathrm{Al}(\mathrm{HCis})\left(\mathrm{H}_{2} \mathrm{O}\right)_{4}\right]^{2+}$ e para o ligante homocisteína

Tabela 7.8 - Parâmetros geométricos calculados (ângulos de ligação em graus) para o complexo $\left[\mathrm{Al}(\mathrm{HCis})\left(\mathrm{H}_{2} \mathrm{O}\right)_{4}\right]^{2+}$ e para o ligante homocisteína

Tabela 7.9 - Espectro vibracional Raman experimental e calculado para o complexo $\left[\mathrm{Al}(\mathrm{Hcis})\left(\mathrm{H}_{2} \mathrm{O}\right)_{4}\right]^{2+}$

Tabela 7.10 - Parâmetros geométricos calculados (comprimentosde ligação em $\AA$ ) para o complexo fac- $\left[\mathrm{Al}(\mathrm{Pen})\left(\mathrm{H}_{2} \mathrm{O}\right)_{3}\right]^{+}$e para o ligante penicilamina

Tabela 7.11 - Parâmetros geométricos calculados (ângulos de ligação em graus) para o complexo fac- $\left[\mathrm{Al}(\mathrm{Pen})\left(\mathrm{H}_{2} \mathrm{O}\right)_{3}\right]^{+}$e para o ligante penicilamina

Tabela 7.12 - Espectro vibracional Raman experimental e calculado para o complexo fac-[Al(Pen) $\left.\left(\mathrm{H}_{2} \mathrm{O}\right)_{3}\right]^{+}$

Tabela 7.13 - Parâmetros geométricos - Comprimentos de ligação

Tabela 7.14 - Média da ligação Al-O $\left(\mathrm{H}_{2} \mathrm{O}\right)$

Tabela 7.15 - Diferença entre a ligação Al-O da água coordenada e a ligação Al-O do carboxilato

Tabela 7.16 - Energia de estabilização calculada no vácuo para os complexos AlL

Tabela 7.17 - Parâmetros geométricos calculados (comprimentos de ligação em $\AA$ ) para o complexo $\left[\mathrm{Al}(\mathrm{PCr})\left(\mathrm{H}_{2} \mathrm{O}\right)\right]^{+}$e para o ligante fosfocreatina

Tabela 7.18 - Parâmetros geométricos calculados (ângulos de ligação em graus) para o complexo $\left[\mathrm{Al}(\mathrm{PCr})\left(\mathrm{H}_{2} \mathrm{O}\right)\right]^{+}$e para o ligante fosfocreatina

Tabela 7.19 - Espectro vibracional Raman experimental e calculado para o complexo $\left[\mathrm{Al}(\mathrm{PCr})\left(\mathrm{H}_{2} \mathrm{O}\right)\right]^{+}$

Tabela 7.20 - Parâmetros geométricos calculados (comprimentos de ligação em $\AA$ ) para o complexo $\left[\mathrm{Al}(\mathrm{ATP})\left(\mathrm{H}_{2} \mathrm{O}\right)_{4}\right]^{+}$e para o ligante adenosina 5 -trifosfato 
Tabela 7.21 - Parâmetros geométricos calculados (ângulos de ligação em graus) para o complexo [Al(ATP) $\left.\left(\mathrm{H}_{2} \mathrm{O}\right)_{4}\right]^{+}$e para o ligante adenosina 5 '-trifosfato

Tabela 7.22 - Espectro vibracional Raman experimental e calculado para o complexo $\left[\mathrm{Al}(\mathrm{ATP})\left(\mathrm{H}_{2} \mathrm{O}\right)_{4}\right]^{+}$

Tabela 8.1 - Valores de log $\beta_{\text {AlL }}$ para os complexos em estudo e $\log \beta_{H L}$ para os ligantes

Tabela 8.2 - Valores de $\log \beta_{\mathrm{HL}}$ e $\log \beta_{\text {AIL }}$ para o IDA e MIDA

Tabela A.1 - Titulação potenciométrica dos ligantes Pen, Cis, Hcis e Met

Tabela A.2 - Titulação potenciométrica dos sistemas Al:aa na proporção 1:1

Tabela A.3 - Titulação potenciométrica dos sistemas Al:aa na proporção 1:5

Tabela A.4 - Número de onda nos espectros Raman da água bidestilada e da solução de nitrato de alumínio 0,5 mol. $\mathrm{L}^{-1}$

Tabela A.5 - Atribuições aproximadas dos espectros experimentais e calculados para o complexo $\left[\mathrm{Al}(\mathrm{Met})\left(\mathrm{H}_{2} \mathrm{O}\right)_{4}\right]^{2+}$ e para o ligante metionina

Tabela A.6 - Atribuições aproximadas dos espectros experimentais e calculados para o complexo $\left[\mathrm{Al}(\mathrm{Cis})\left(\mathrm{H}_{2} \mathrm{O}\right)_{4}\right]^{2+}$ e para o ligante cisteína

Tabela A.7 - Atribuições aproximadas dos espectros experimentais e calculados para o complexo $\left[\mathrm{Al}(\mathrm{Hcis})\left(\mathrm{H}_{2} \mathrm{O}\right)_{4}\right]^{2+}$ e para o ligante homocisteína

Tabela A.8 - Atribuições aproximadas dos espectros experimentais e calculados para o complexo $\left[\mathrm{Al}(\mathrm{Pen})\left(\mathrm{H}_{2} \mathrm{O}\right)_{3}\right]^{+}$e para o ligante penicilamina

Tabela A.9 - Atribuições aproximadas dos espectros experimentais e calculados para o complexo $\left[\mathrm{Al}(\mathrm{PCr})\left(\mathrm{H}_{2} \mathrm{O}\right)\right]^{+}$e para o ligante fosfocreatina

Tabela A.10 - Atribuições aproximadas dos espectros experimentais e calculadospara o complexo [Al (ATP $\left.)\left(\mathrm{H}_{2} \mathrm{O}\right)_{4}\right]^{+}$e para o ligante ATP 


\section{Lista de símbolos e abreviações}

RMN - Ressonância Magnética Nuclear

RMI - Ressonância Magnética Nuclear por imagem

DA - doença de Alzheimer

aa - aminoácidos

$\mathrm{L}$ - ligante

I - força iônica

f.e.m. - força eletromotriz

SERS - sinal Raman por efeitos de superfície

DFT - teoria do funcional de densidade

$\mathrm{HF}$ - hartree fock

$\mathrm{D}_{2} \mathrm{O}$ - água deuterada

TMSP-2,2,3,3-D4 - 2,2,3,3-d4-(3- trimetilsilil)-propionato de sódio

TMS - trimetilsilano

EDDA - ácido 1,2-diaminoetano-N,N'-dietanóico

EDDPA - ácido etilenodiamino-N,N'-dipropanóico

HEIDA - ácido N-(2-hidroxietil)iminoetanóico

IDA - ácido iminodiacético

NTA - ácido nitrilotrietanóico

MIDA - ácido metil-iminodiacético

Gli - glicina

$\alpha$-Ala - $\alpha$-alanina

$\beta$-Ala - $\beta$-alanina

Ile - isoleucina

Leu - leucina

Ser - serina

Tir - tirosina

Tre - treonina

Val - valina

Met - metionina

Cis - cisteína

Hcis - homocisteína

Pen - penicilamina

$\mathrm{PCr}$ - fosfocreatina

ATP - adenosina 5'-trifosfato

GAA - ácido guanidino acético 